\title{
Room-Temperature Synthesis of Cobalt Nanoparticles by Electroless Deposition in Aqueous Solution
}

\section{$\operatorname{AUTHOR}(\mathrm{S}):$}

Balela, Mary Donnabelle L.; Yagi, Shunsuke; Matsubara, Eiichiro

\section{CITATION:}

Balela, Mary Donnabelle L....[et al]. Room-Temperature Synthesis of Cobalt Nanoparticles by Electroless Deposition in Aqueous Solution. ELECTROCHEMICAL AND SOLID STATE LETTERS 2010, 13(2): D4-D6

\section{ISSUE DATE:}

2010

URL:

http://hdl.handle.net/2433/109933

RIGHT:

(C) 2010 The Electrochemical Society 


\title{
Room-Temperature Synthesis of Cobalt Nanoparticles by Electroless Deposition in Aqueous Solution
}

\author{
Mary Donnabelle L. Balela, ${ }^{\mathrm{z}}$ Shunsuke Yagi, ${ }^{*}$ and Eiichiro Matsubara
}

Department of Materials Science and Engineering, Kyoto University, Kyoto 606-8501, Japan

Metallic Co nanoparticles of 24-110 nm diameters are prepared by electroless deposition (chemical reduction) in an aqueous solution at room temperature. The reduction process is monitored by an in situ measurement of a mixed potential. The mixed potential, which is above the redox potential of a $\mathrm{Co}(\mathrm{II}) / \mathrm{Co}$ redox pair, drops by the addition of the nucleating agent $\mathrm{H}_{2} \mathrm{PtCl}_{6}$ and also decreases with an increase in the $\mathrm{H}_{2} \mathrm{PtCl}_{6}$ concentration. Smaller Co nanoparticles are formed. In the smaller particle size, the fraction of the face-centered cubic Co phase increases, and the hexagonal close-packed Co phase decreases. (C) 2009 The Electrochemical Society. [DOI: 10.1149/1.3265525] All rights reserved.

Manuscript submitted October 2, 2009; revised manuscript received October 27, 2009. Published November 18, 2009.

Co nanoparticles have great scientific and technological importance due to their unique properties that are different from the bulk. ${ }^{1-4}$ The formation of Co nanoparticles has been extensively studied over the years, leading to a wide variety of synthesis methods, such as thermal decomposition, micellar reduction, sonochemical reduction, and simple chemical (solution) reduction. ${ }^{1-9}$ Most of the methods are conducted in an organic solvent at an elevated temperature because the fabrication of Co nanoparticles at room temperature is still challenging, specifically in an aqueous solution. This is due to the difficulty of formation of size-controlled Co nanoparticles without agglomeration and oxidation. The reducing agent, such as sodium borohydride, can reduce $\mathrm{Co}$ (II) ions at room temperature. ${ }^{3-5}$ However, the synthesized Co nanoparticles are usually polydispersed and amorphous containing boron. ${ }^{3,4}$

In this article, we present a method of preparation of Co nanoparticles with diameters of $24-110 \mathrm{~nm}$ by electroless deposition (chemical reduction) with hydrazine monohydrate $\left(\mathrm{N}_{2} \mathrm{H}_{4} \cdot \mathrm{H}_{2} \mathrm{O}\right)$ as a reducing agent in an aqueous solution at room temperature. Chloroplatinic acid hexahydrate $\left(\mathrm{H}_{2} \mathrm{PtCl}_{6} \cdot 6 \mathrm{H}_{2} \mathrm{O}\right)$ is used as a nucleating agent. The effects of the nucleating agent on the particle morphology and deposition rates are studied by electron microscopy and in situ mixed potential measurements, respectively.

\section{Experimental}

All chemical reagents were analytical grade (Nacalai Tesque). A $\mathrm{Co}(\mathrm{II})$ aqueous solution was prepared by dissolving $0.01 \mathrm{~mol} \mathrm{Co}(\mathrm{II})$ acetate tetrahydrate $\left[\mathrm{Co}\left(\mathrm{C}_{2} \mathrm{H}_{3} \mathrm{O}_{2}\right)_{2} \cdot 4 \mathrm{H}_{2} \mathrm{O}\right]$ and $1.3 \times 10^{-4} \mathrm{~mol}$ poly(ethylene glycol) $\left[\mathrm{H}\left(\mathrm{OCH}_{2} \mathrm{CH}_{2}\right) \mathrm{nOH}, M_{\mathrm{w}}=20,000\right]$ in $50 \mathrm{~mL}$ deoxygenated water. Then, $1 \mathrm{M}$ sodium hydroxide $(\mathrm{NaOH})$ aqueous solution of $25 \mathrm{~mL}$ was added to provide $\mathrm{OH}^{-}$ions. Next, 2.5 $\times 10^{-6}$ to $2.5 \times 10^{-4} \mathrm{~mol} \mathrm{H}_{2} \mathrm{PtCl}_{6} \cdot 6 \mathrm{H}_{2} \mathrm{O}$ in a propylene glycol $\left(\mathrm{C}_{3} \mathrm{H}_{8} \mathrm{O}_{2}\right)$ solution of $10 \mathrm{~mL}$ was added as the nucleating agent. The reducing agent solution was prepared by mixing $0.1 \mathrm{~mol} \mathrm{~N}_{2} \mathrm{H}_{4} \cdot \mathrm{H}_{2} \mathrm{O}$ in $25 \mathrm{~mL}$ deoxygenated $\mathrm{C}_{3} \mathrm{H}_{8} \mathrm{O}_{2}$. The $\mathrm{N}_{2} \mathrm{H}_{4} \cdot \mathrm{H}_{2} \mathrm{O}-\mathrm{C}_{3} \mathrm{H}_{8} \mathrm{O}_{2}$ solution was then added into the $\mathrm{Co}$ (II) aqueous solution at room temperature, while the solution was continuously stirred and nitrogen gas $\left(\mathrm{N}_{2}\right)$ was bubbled at $50 \mathrm{~mL} / \mathrm{min}$. The $\mathrm{pH}$ value of the total solution was about 12 . The total volume was $115 \mathrm{~mL}$, and the final concentrations were $0.087 \mathrm{M} \mathrm{Co}(\mathrm{II})$ acetate tetrahydrate, $1.1 \mathrm{mM}$ poly(ethylene glycol), $0.22 \mathrm{M} \mathrm{NaOH}, 0.022-2.2 \mathrm{mM} \mathrm{H}_{2} \mathrm{PtCl}_{6} \cdot 6 \mathrm{H}_{2} \mathrm{O}$, and $0.87 \mathrm{M} \mathrm{N}_{2} \mathrm{H}_{4} \cdot \mathrm{H}_{2} \mathrm{O}$. After the solution was kept for $1 \mathrm{~h}$, Co nanoparticles were magnetically separated and washed several times with ethanol.

The morphology of Co nanoparticles was observed by a fieldemission-scanning electron microscope (JEOL JSM 6500-F) and a transmission electron microscope (TEM, JEOL JEM 2010). The mean diameter was determined by image analyses for 300 nanoparticles in each sample. The structure was analyzed by X-ray diffrac-

\footnotetext{
Electrochemical Society Active Member

z E-mail: balela.m@hw8.ecs.kyoto-u.ac.jp
}

tion (XRD) using $\mathrm{Cr} \mathrm{K} \alpha$ radiation (MAC Science M03XHF22), The mixed potential in the reaction solution was measured by a potentiostat/galvanostat (Hokuto Denko Co. Ltd., HA-151) using Pt-sputtered quartz crystal substrates as working electrodes. A Ag/ $\mathrm{AgCl}$ electrode $[0.206 \mathrm{~V}$ vs standard hydrogen electrode (SHE) at $25^{\circ} \mathrm{C}$, Horiba $2565-10 \mathrm{~T}$ ], immersed in $3.33 \mathrm{M} \mathrm{KCl}$ aqueous solution, was used as a reference electrode so that the measured mixed potentials were converted to the values against SHE.

\section{Results and Discussion}

In the present process, several cathodic and anodic partial reactions occur simultaneously. The main cathodic partial reactions are Pt deposition, Co deposition, and $\mathrm{H}_{2}$ generation. Because the oxidation-reduction potential of the $\mathrm{Pt}(\mathrm{IV}) / \mathrm{Pt}$ redox pair is more positive than those of $\mathrm{Co}(\mathrm{II}) / \mathrm{Co}$ and $\mathrm{H}_{2} \mathrm{O} / \mathrm{H}_{2}$ redox pairs, $\mathrm{Pt}(\mathrm{IV})$ ions from the nucleating agent $\mathrm{H}_{2} \mathrm{PtCl}_{6}$ are first reduced by hydrazine to form minute Pt nanoparticles. The $\mathrm{Co}$ (II) ions are then reduced by hydrazine, and the Co atoms are deposited preferentially on the surface of the Pt nanoparticles, which are the heterogeneous nucleation sites of Co nanoparticles. Co deposition occurs concurrently with the hydrogen generation. The main cathodic partial reactions can be written as

Pt deposition

$$
\mathrm{Pt}(\mathrm{IV})+4 \mathrm{e} \rightarrow \mathrm{Pt}
$$

Co deposition

$$
\mathrm{Co}(\mathrm{II})+2 \mathrm{e} \rightarrow \mathrm{Co}
$$

$\mathrm{H}_{2}$ generation

$$
2 \mathrm{H}_{2} \mathrm{O}+2 \mathrm{e} \rightarrow \mathrm{H}_{2}+2 \mathrm{OH}^{-}
$$

Anodic partial reactions are primarily hydrazine oxidation reactions

$$
\begin{gathered}
\mathrm{N}_{2} \mathrm{H}_{4}+4 \mathrm{OH}^{-} \rightarrow \mathrm{N}_{2}+4 \mathrm{H}_{2} \mathrm{O}+4 \mathrm{e} \\
\mathrm{N}_{2} \mathrm{H}_{4}+\mathrm{OH}^{-} \rightarrow \frac{1}{2} \mathrm{~N}_{2}+\mathrm{NH}_{3}+\mathrm{H}_{2} \mathrm{O}+\mathrm{e}
\end{gathered}
$$

Therefore, the overall cobalt deposition reactions can be obtained by combining Reactions 2-5 as follows

$$
\begin{gathered}
\mathrm{Co}(\mathrm{II})+\frac{1}{2} \mathrm{~N}_{2} \mathrm{H}_{4}+2 \mathrm{OH}^{-} \rightarrow \mathrm{Co}+\frac{1}{2} \mathrm{~N}_{2}+2 \mathrm{H}_{2} \mathrm{O} \\
\mathrm{Co}(\mathrm{II})+2 \mathrm{~N}_{2} \mathrm{H}_{4}+2 \mathrm{OH}^{-} \rightarrow \mathrm{Co}+\mathrm{N}_{2}+2 \mathrm{NH}_{3}+2 \mathrm{H}_{2} \mathrm{O}
\end{gathered}
$$

Figure 1 shows the change in the mixed potentials during the reactions in the aqueous solutions containing different concentrations of nucleating agent, $\mathrm{H}_{2} \mathrm{PtCl}_{6}$. From the thermodynamical viewpoint, Co can be deposited when the mixed potential is less than the oxidation-reduction potential of the $\mathrm{Co}(\mathrm{II}) / \mathrm{Co}$ redox pair $\left(E_{\mathrm{Co}(\mathrm{II}) / \mathrm{Co}}\right)$ calculated by the Nernst equation and the activity of $\mathrm{Co}^{2+}$ aquo ions of about $8.2 \times 10^{-12}$ in equilibrium with abundant $\mathrm{Co}(\mathrm{OH})_{2}$ at $\mathrm{pH}$ $12 .{ }^{7-9}$ Because the mixed potentials without $\mathrm{H}_{2} \mathrm{PtCl}_{6}$ are fluctuated, their average values are plotted in Fig. 1a. The instability of the mixed potentials is due to the very small current densities during the 


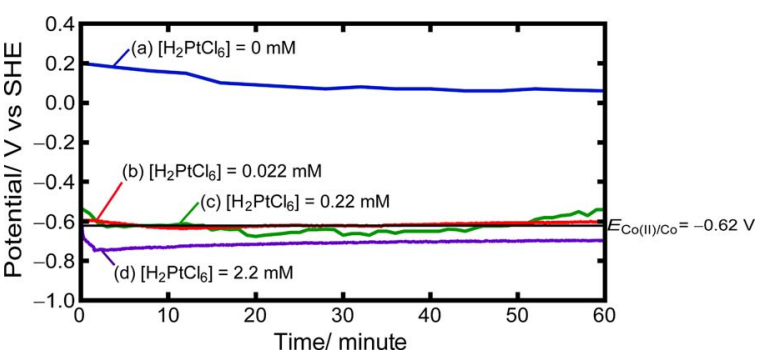

Figure 1. (Color online) Changes in mixed potentials during electroless deposition of Co nanoparticles containing (a) 0, (b) 0.022, (c) 0.22, and (d) $2.2 \mathrm{mM} \mathrm{H}_{2} \mathrm{PtCl}_{6}$ nucleating agent.

reaction. The average values are obviously much larger than $E_{\mathrm{Co}(\mathrm{II}) / \mathrm{Co}}=-0.62 \mathrm{~V}$ throughout the reaction. Naturally, no Co nanoparticles are formed even after $2 \mathrm{~h}$.

In contrast, the mixed potentials shift more negatively, and the reduction of $\mathrm{Co}$ (II) ions occurs faster with an increase in the concentration of $\mathrm{H}_{2} \mathrm{PtCl}_{6}$. In the presence of $0.022 \mathrm{mM} \mathrm{H}_{2} \mathrm{PtCl}_{6}$, the mixed potential drops to $E_{\mathrm{Co}(\mathrm{II}) / \mathrm{Co}}$ about $5 \mathrm{~min}$ after the addition of $\mathrm{N}_{2} \mathrm{H}_{4}$, and the color of the solution changes to black. When $\mathrm{H}_{2} \mathrm{PtCl}_{6}$ is $0.22 \mathrm{mM}$, the mixed potential is equal to $E_{\mathrm{Co}(\mathrm{II}) / \mathrm{Co}}$ after about 2 min, and the reduction of $\mathrm{Co}$ (II) ions occurs simultaneously. Further increase in the $\mathrm{H}_{2} \mathrm{PtCl}_{6}$ concentration results in an instantaneous drop of the mixed potentials below $E_{\mathrm{Co}(\mathrm{II}) / \mathrm{Co}}$ and a spontaneous change in the color of the solution. Because of the acceleration of the reaction rates with the nucleating agent, it is plausible that the $\mathrm{Pt}$ nanoparticles formed from $\mathrm{H}_{2} \mathrm{PtCl}_{6}$ act as catalysts for $\mathrm{Co}$ (II) reduction, as well as nucleation sites for $\mathrm{Co}$ nanoparticles. It has been reported that hydrazine is catalytically oxidized on the surface of $\mathrm{Pt}$ nanoparticles. ${ }^{10}$ Thus, the reduction of $\mathrm{Co}$ (II) ions is accelerated at the surface of the Pt nanoparticles, which are simultaneously the heterogeneous nucleation sites of Co nanoparticles. Small Co nanoparticles are then formed. The decrease in the mixed potential with the increase in the concentration of $\mathrm{H}_{2} \mathrm{PtCl}_{6}$ is explained by considering that the mixed potential is mainly controlled by a change in the current density for hydrazine oxidation. The oxidation of hydrazine is generally slow at room temperature. However, the addition of $\mathrm{H}_{2} \mathrm{PtCl}_{6}$ accelerates the oxidation reaction due to the catalytic activity of the small Pt nanoparticles. The current density for hydrazine oxidation therefore increases, which reduces the mixed potential. During the precipitation of the Co nanoparticles, significant gas evolution occurs and a large concentration of hydrazine in the solution is depleted. This leads to a gradual increase in the mixed potentials in Fig. 1b-d.

The scanning electron microscope (SEM) images of the Co nanoparticles synthesized by the present method are shown in Fig. 2. The mean particle size of the Co nanoparticles decreases with an increase in the concentration of $\mathrm{H}_{2} \mathrm{PtCl}_{6}$, which shows that the nucleating agent apparently works as nuclei of the Co nanoparticles. ${ }^{1}, 12$ The smallest Co nanoparticles of $24 \mathrm{~nm}$ in diameter are obtained with the addition of $2.2 \mathrm{mM} \mathrm{H}_{2} \mathrm{PtCl}_{6}$. The relative standard deviations of the sample size are about $12-16 \%$. Quite

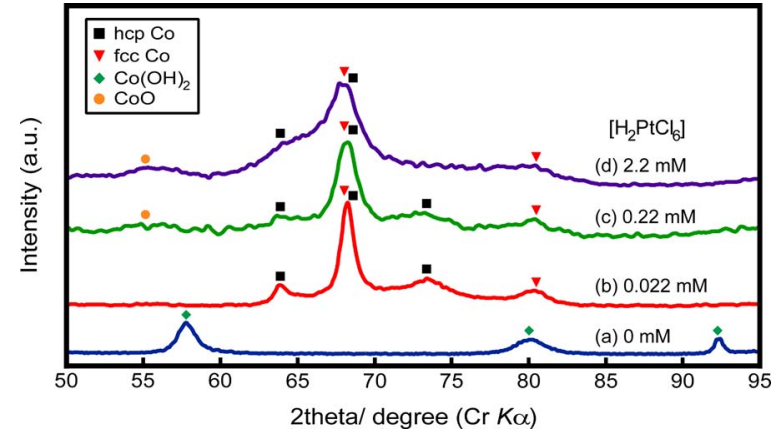

Figure 3. (Color online) XRD patterns of the Co nanoparticles synthesized in solutions containing (a) 0 , (b) 0.022 , (c) 0.22 , and (d) $2.2 \mathrm{mM} \mathrm{H}_{2} \mathrm{PtCl}_{6}$ nucleating agent.

narrow size distributions are obtained. The Co nanoparticles are interlinked at random directions, which is due to the magnetic attraction among the nanoparticles.

XRD profiles of the products prepared in the solutions containing various concentrations of the nucleating agent $\mathrm{H}_{2} \mathrm{PtCl}_{6}$ are shown in Fig. 3. Without adding the nucleating agent, only the peaks of $\mathrm{Co}(\mathrm{OH})_{2}$, which is the intermediate product during the reaction, are present, as shown in Fig. 3a. Both hexagonal close-packed (hcp) and face-centered cubic (fcc) Co nanoparticles are fabricated in the solutions containing the nucleating agents. These XRD profiles are consistent with the change in the mixed potentials in Fig. 1.

The strongest peak at $68.0^{\circ}$ and the peak at $80.5^{\circ}$ are due to 111 and $200 \mathrm{fcc} \mathrm{Co}$, respectively. The peak width becomes larger with an increase in the concentration of $\mathrm{H}_{2} \mathrm{PtCl}_{6}$. This indicates that the crystallite sizes of the $\mathrm{Co}$ nanoparticles decrease in the solution containing the larger $\mathrm{H}_{2} \mathrm{PtCl}_{6}$ concentration. This result coincides with the change in the particle morphology by SEM.

The distinct 100 and 101 hcp Co peaks are also present at $63.8^{\circ}$ and $73.6^{\circ}$, respectively. Though the $002 \mathrm{hcp}$ Co peak exists at $68.9^{\circ}$, it is concealed by the large $111 \mathrm{fcc}$ Co peak. Besides, because the maximum hcp Co peak is 101 at $73.6^{\circ}$, the fcc Co phase is dominant in the present Co nanoparticles. This is consistent with the previous study that the major crystalline structure of $\mathrm{Co}$ is fcc in the nanoparticles, and this tendency becomes significant in the smaller particles. $12-14$

In the XRD profiles in Fig. 3c and d, a very diffused peak exists at $55.5^{\circ}$. This peak is ascribed to $\mathrm{CoO} 111$. Thus, the very thin surface layer of Co nanoparticles of smaller sizes, i.e., 24-54 $\mathrm{nm}$ in diameter, is oxidized. This $\mathrm{CoO}$ is formed during the washing process and the XRD measurements after the reaction.

\section{Conclusion}

The catalytic property of the nucleating agent $\mathrm{H}_{2} \mathrm{PtCl}_{6}$ enables us to prepare metallic Co nanoparticles of 24-110 nm diameter at room temperature by electroless deposition (chemical reduction) with hydrazine in aqueous solution. The $\mathrm{Co}$ (II) reduction rate and the mean particle size of the Co nanoparticles strongly depend on the concentration of $\mathrm{H}_{2} \mathrm{PtCl}_{6}$, which are observed by in situ measurements of
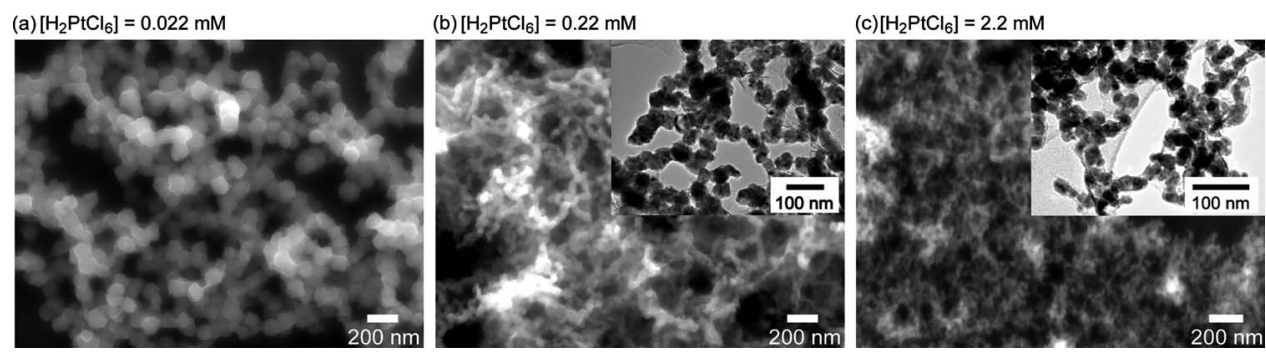

Figure 2. SEM images of Co nanoparticles prepared using (a) 0.02 , (b) 0.22 and (c) $2.2 \mathrm{mM} \mathrm{H}_{2} \mathrm{PtCl}_{6}$ nucleating agent. The mean diameters of the Co nanoparticles are (a) 112, (b) 54, and (c) $24 \mathrm{~nm}$ Insets are the TEM images of the $\mathrm{Co}$ nanoparticles. 
the mixed potential. In the presence of the nucleating agent, the mixed potential quickly drops below the oxidation-reduction poten-

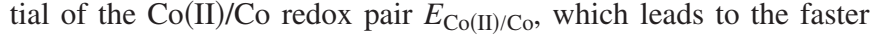
$\mathrm{Co}(\mathrm{II})$ reduction and the formation of smaller Co nanoparticles. In contrast, without adding nucleating agents, the mixed potential is above $E_{\mathrm{Co}(\mathrm{II}) / \mathrm{Co}}$, and no Co nanoparticle is prepared.

\section{Acknowledgments}

The authors express their gratitude to Kenji Kazumi for the assistance in TEM observation. This research was supported by a grant-in-aid for Knowledge Cluster Initiative (Kyoto Nanotechnology Cluster), grant-in-aid for the Global COE Program (International Center for Integrated Research and Advanced Education in Materials Science), and grant-in-aid for Young Scientists (B20760505), all from the Japan Society for the Promotion of Science, Ministry of Education, Culture, Sports, Science and Technology of Japan. This research was also supported by the Kurata Memorial Hitachi Science and Technology Foundation and Shorai Foundation for Science and Technology.

Kyoto University assisted in meeting the publication costs of this article.

\section{References}

1. S. S. Kalyan Kamal, P. K. Sahoo, M. Premkumar, N. V. Rama Rao, T. Jagadeesh Kumar, B. Sreedhar, A. K. Singh, S. Ram, and K. Chandra Sekhar, J. Alloys Compd., 474, 214 (2009).

2. H. Li and S. Liao, Solid State Commun., 115, 118 (2008).

3. V. Salgueiriño-Maceira, M. A. Correa-Duarte, M. Farle, M. A. Lopez-Quintela, K. Sieradzki, and R. Diaz, Langmuir, 22, 1455 (2006).

4. Y.-W. Zhao, R. K. Zheng, X. X. Zhang, and J. Q. Xiao, IEEE Trans. Magn., 39, 2764 (2003).

5. Y. Chen, K. Y. Liew, and J. Li, Appl. Surf. Sci., 255, 4039 (2009).

6. C. P. Gibson and K. J. Putzer, Science, 267, 1338 (1995).

7. S. Yagi, H. Nakanishi, E. Matsubara, S. Matsubara, T. Ichitsubo, K. Hosoya, and Y. Matsuba, J. Electrochem. Soc., 155, D474 (2008).

8. S. Yagi, T. Koyanagi, H. Nakanishi, T. Ichitsubo, and E. Matsubara, J. Electrochem. Soc., 155, D583 (2008).

9. S. Yagi, H. Nakanishi, T. Ichitsubo, and E. Matsubara, J. Electrochem. Soc., 156 D321 (2009).

10. M. Grzelczak, J. Perez-Juste, B. Rodriguez-Gonzales, M. Spasova, I. Barsukov, M. Farle, and L. M. Liz-Marzan, Chem. Mater, 20, 5399 (2008).

11. T. Sugimoto, Monodispersed Particles, pp. 368-377, Elsevier, Amsterdam (2001).

12. M. D. L. Balela, S. Yagi, Z. Lockman, A. Aziz, A. V. Amorsolo, Jr., and E. Matsubara, J. Electrochem. Soc., 156, E139 (2009).

13. T. Hinotsu, B. Jeyadevan, C. N. Chinnasamy, K. Shinoda, and K. Tohji, J. Appl. Phys., 95, 7477 (2004).

14. N. Chakroune, G. Viau, C. Ricolleau, F. Fiévet-Vincent, and F. Fiévet, J. Mater Chem., 13, 312 (2003). 